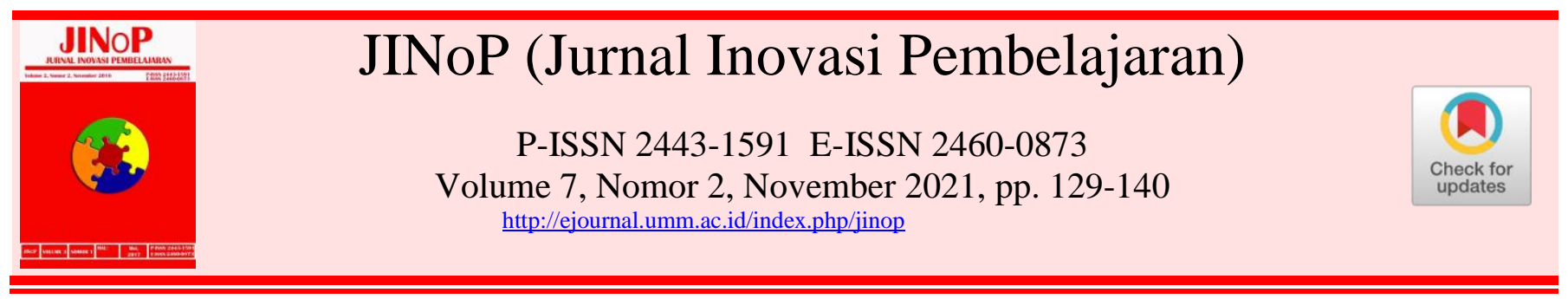

\title{
Pengembangan aplikasi CPA (Covid-19 Prevention Application) sebagai literasi mitigasi bencana Covid-19 bagi siswa SMP
}

\author{
Alifian Nabila $^{1 \text { * }}$, Neni Wahyuningtyas ${ }^{2)}$, Agung Wiradimadja ${ }^{3)}$. \\ ${ }^{1}$ Program Studi IPS, Fakultas Ilmu Sosial, Universitas Negeri Malang, Jalan Semarang Nomor 5, \\ Malang, Indonesia. \\ ${ }^{2}$ Program Studi IPS, Fakultas Ilmu Sosial, Universitas Negeri Malang, Jalan Semarang Nomor 5, \\ Malang, Indonesia. \\ ${ }^{3}$ Program Studi IPS, Fakultas Ilmu Sosial, Universitas Negeri Malang, Jalan Semarang Nomor 5, \\ Malang, Indonesia.
}

alifian.nabila.1707416@students.um.ac.id* ; neni.wahyuningtyas.fis@um.ac.id ; agung.wiradimadja.fis@um.ac.id

*Penulis Koresponden

\begin{tabular}{|c|c|}
\hline ABSTF & \\
\hline $\begin{array}{l}\text { Pandemi Covid-19 telah membawa perubahan bes } \\
\text { bidang Pendidikan yaitu dengan pembelajaran onlin } \\
\text { diperlukan adanya adaptasi dan penyesuaian siswa de } \\
\text { dalam pembelajaran menjadi sangat dibutuhkan, s } \\
\text { bencana Covid-19 bagi siswa dengan pengemba } \\
\text { Application) berbasis Ebook. Tujuan adanya pen } \\
\text { menghasilkan produk Aplikasi CPA; (2) menguji tin } \\
\text { pembelajaran. Materi yang dimuat dalam aplikasi } \\
\text { dikaitkan pada materi pembelajaran IPS SMP yait } \\
\text { pengembangan ini menggunakan model modifikasi } \\
\text { Malang dengan sampel siswa kelas IX.1. Penerapan } \\
\text { relevan dengan teori bejara konstruktivisme, teori } \\
\text { belajar sibernetik. Hasil penelitian menyatakan bah } \\
\text { kriteria sangat layak untuk diterapkan dalam pemb } \\
\text { mampu menjadi media yang solutif untuk memb } \\
\text { bencana Covid-19 dalam pembelajaran yang menari } \\
\text { melakukan uji coba skala besar dengan mengukur ti } \\
\text { Kata kunci: Aplikasi CPA; Literasi; Mitigasi Bence }\end{array}$ & $\begin{array}{l}\text { dalam pola masyarakat, salah satunya di } \\
\text { Hal tersebut memunculkan stigma bahwa } \\
\text { ran kebijakan pembelajaran online. Inovasi } \\
\text { h satu bentuknya adalah literasi mitigasi } \\
\text { an aplikasi CPA (Covid-19 Prevention } \\
\text { tian dan pengembangan ini adalah, (1) } \\
\text { t kelayakan Aplikasi CPA sebagai sumber } \\
\text { PA yaitu tentang mitigasi bencana yang } \\
\text { erubahan sosial kelas IX. Penelitian dan } \\
\text { rg \& Gall dan dilaksanakan di SMPN } 21 \\
\text { likasi CPA dalam pembelajaran ini dinilai } \\
\text { rucut pengalaman Edgar Dale, dan teori } \\
\text { a pengembangan Aplikasi CPA memiliki } \\
\text { jaran. Kesimpulannya, pengembangan ini } \\
\text { kan edukasi pada siswa dalam mitigasi } \\
\text { Saran pada penelitian ini diharapkan dapat } \\
\text { kat efektivitasnya. }\end{array}$ \\
\hline \multicolumn{2}{|c|}{ ABSTRACT } \\
\hline $\begin{array}{l}\text { The Covid-19 pandemic has brought major change } \\
\text { activities are conducted online. It is thus necessary } \\
\text { innovation is urgently needed. Among the innovatic } \\
\text { Application (CPA) that contains Covid-19 disaster } \\
\text { aims to: 1) produce an app for CPA; and 2) test th } \\
\text { resource. The material in CPA app relates to disa } \\
\text { Learning for junior high schools, namely Social Cha } \\
21 \text { Malang. This research and development modifi } \\
\text { constructivism learning theory, Edgar Dale's thec } \\
\text { theory. Results show that the development of the CPA } \\
\text { that CPA app offers solutions to help students in miti } \\
\text { learning. It is suggested that further large-scale tria } \\
\text { the level of effectiveness. } \\
\text { Keywords: CPA App; Literacy; Disaster Mitigation }\end{array}$ & $\begin{array}{l}\text { including education where most learning } \\
\text { adapt into online learning policies where } \\
\text { is an e-book titled Covid-19 Prevention } \\
\text { gation literacy for students. This research } \\
\text { easibility level of CPA app as a learning } \\
r \text { mitigation, linked to the Social Studies } \\
\text { e for the } 9^{\text {th }} \text { graders (Class IX.1) at SMPN } \\
\text { Borg \& Gall model, which is relevant to } \\
\text { of experience, and cybernetic learning } \\
\text { pp is "highly feasible". This result implied } \\
\text { ing the Covid-19 disaster through creative } \\
\text { vill be conducted in the future to measure }\end{array}$ \\
\hline
\end{tabular}


diunggah: 2021/06/02, direvisi: 2021/11/15, diterima: 2021/11/22,dipublikasi: 2021/11/30

Copyright (c) 2021 Nabila et al

This is an open access article under the CC-BY license

Cara sitasi: Nabila, A. ., Wahyuningtyas, N. ., \& Wiradimadja, A. . (2021). Pengembangan aplikasi "CPA" (Covid-19 prevention application) sebagai literasi mitigasi bencana covid-19 bagi siswa SMP. JINoP (Jurnal Inovasi Pembelajaran), 7(2). https://doi.org/10.22219/jinop. v7i2.16761

\section{PENDAHULUAN}

Pandemi Covid-19 merupakan fenomena yang terjadi dalam kurun waktu setahun ini dan telah membawa banyak perubahan dalam tatanan kehidupan masyarakat. Perubahan tersebut merupakan bentuk penyesuaian akibat banyaknya korban yang terdampak Covid-19. Bahkan, dalam kurun waktu satu tahun sudah terdapat satu juta kasus di Indonesia dan memakan lebih dari 40.000 korban meninggal akibatnya (WHO Indonesia, 2020). Menyikapi kilas balik Covid-19 yang cukup membawa banyak dampak dalam kehidupan masyarakat, Pemerintah Indonesia mengeluarkan kebijakan-kebijakan untuk memutus mata rantai penyebaran Covid-19 (Hairi, 2020). Salah satu kebijakan tersebut adalah pelaksanaan sekolah yang dirumahkan dan pembelajaran dialihkan menggunakan online. Pembelajaran online merupakan pembelajaran yang memanfaatkan jaringan internet dengan dan didukung dengan kelas virtual (Firman \& Rahayu, 2020). Kebijakan kegiatan sekolah di rumah tak lain halnya berkaitan dengan penekanan penyebaran Covid-19 mengingat di sekolah juga terdapat penyebaran Covid-19. Sekiranya dalam waktu 5 bulan saja, terdapat 138 siswa dan santri yang positif Covid-19 dan ratusan lainnya diharuskan karantina mandiri karena melakukan kontak langsung dengan pasien teridentifikasi Covid-19 (Federasi Serikat Guru Indonesia, 2020). Hal tersebut menandakan bahwa perlu adanya edukasi tentang Covid-19 sebagai bentuk mitigasi bencana kepada siswa yang dapat digunakan pada masa pembelajaran online dan sesuai dengan anjuran protokol kesehatan (Marbun, 2020). Maka dari itu, peneliti menyusun penelitian dan pengembangan Aplikasi yang berbasis Ebook agar memiliki kepraktisan dan dapat menarik siswa dalam literasi tentang Covid-19. Ebook dinilai dapat menjadi alternatif yang ramah lingkungan dan mudah diakses sewaktu-waktu (Nabila et al., 2019). Menurut Mohammed et al. (2015), Ebook juga dapat dijadikan sumber belajar yang mudah diakses tanpa terbatas oleh ruang dan waktu.

Pengembangan Aplikasi berbasis Ebook tentunya telah dikaji oleh beberapa peneliti terdahulu. Ebook yang dikaji oleh N. Jannah et al. (2017) merupakan pengembangan Ebook interaktif yang dapat meningkatkan minat belajar bagi siswa SMP. Penelitian ini menunjukkan bahwa penggunaan media berbasis Ebook dapat dinyatakan valid (layak) untuk digunakan dalam pembelajaran, namun pada penelitian ini menggunakan aplikasi bantu dalam mengedit Ebook yang telah tersedia dan belum berbasis animasi. Selain itu, pengembangan berbasis Ebook juga dikaji oleh Wijayanti (2018) dengan memanfaatkan aplikasi berbasis Ebook sebagai media pembelajaran yang menarik bagi pembelajaran. Penelitian ini menjelaskan bahwa penggunaan Ebook dalam pembelajaran dapat mempermudah dalam menjelaskan fenomena-fenomena sesuai dengan pembelajaran. Sama halnya dengan penelitian sebelumnya, penelitian ini juga menggunakan aplikasi berbantuan dan pengoperasiannya menggunakan laptop atau komputer. 
Tentunya beberapa penelitian terdahulu menafsirkan bahwa pengembangan berbasis Ebook memiliki kebermanfaatan terkhususnya dapat menarik minat siswa dalam pembelajaran. Namun, beberapa penelitian terdahulu lebih banyak menggunakan pengembangan dengan menggunakan aplikasi bantu yang memungkinkan terjadinya kesalahan teknis. Selain itu, tidak semua pengembangan aplikasi tersebut dapat diakses melalui smartphone mengingat bahwa saat ini penggunaan smartphone dinilai lebih praktis. Sehingga agar mempermudah pengaksesannya, peneliti mengkaji pengembangan aplikasi berbasis Ebook yang sesuai dengan kebutuhan saat ini yaitu literasi mitigasi bencana yang dikaitkan dengan pembelajaran IPS dengan materi perubahan sosial. maka dari itu peneliti mengangkat judul "Pengembangan Aplikasi CPA (Covid-19 Prevention Application) sebagai Literasi Mitigasi Bencana Covid-19 bagi Siswa SMP”. Pengembangan Aplikasi CPA tentunya dapat membantu pembelajaran agar lebih efektif. Aplikasi CPA memudahkan siswa dalam mengakses banyak materi menggunakan satu platform, hal tersebut menandakan bahwa penggunaan Aplikasi CPA dinilai lebih praktis dengan animasi-animasi yang disajikan akan dapat membangunkan semangat belajar siswa. Siswa akan lebih mudah menerima pengetahuan melalui media yang menarik dan juga dapat membantu membangun pengalaman siswa (Nasution \& Islam, 2018; Lestari \& Adi, 2016).

\section{METODE}

Penelitian dan pengembangan aplikasi CPA menggunakan model Reasearch \& Development (R\&D) yang diadaptasi oleh Gall et al. (2003) dan telah dimodikifikasi oleh peneliti sesuai kebutuhan penelitian. Tahapan dalam penelitian ini berupa tahap I (potensi dan masalah); tahap II (pengumpulan data); tahap III (desain produk); tahap IV (validasi desain yaitu validasi materi dan validasi media); tahap V (revisi desain); tahap VI (uji coba produk); dan tahap VII (revisi produk). Penelitian dan pengembangan ini bertujuan untuk mengukur tingkat kelayakan media agar dapat diaplikasikan kepada siswa sebagai bentuk kepedulian dan upaya mitigasi bencana Covid-19.

Data diambil dari hasil validasi oleh ahli materi dan ahli media serta hasil uji coba kepada siswa sebagai responden. Cara dalam menentukan responden saat uji coba yaitu dengan menggunakan teknik random sampling. Pengumpulan data dilaksanakan dengan membagikan kuesioner kepada ahli materi, ahli media, dan siswa yang berfungsi untuk mempermudah responden dalam menilai kelayakan media. Data pada penelitian ini berupa data kuantitatif yang diambil berdasarkan rekapitulais hasil validasi desain dan hasil uji coba dan data kualitatif yang diambil dari rekomendasi \& saran dari ahli materi, ahli media, dan siswa. Usai data telah terkumpul, agar dapat mengetahui tingkat kelayakannya maka dilaksanakan analisis data menggunakan rumus sebagai berikut:

$P=\frac{\sum x}{\sum x i} \mathrm{X} 100 \%$

Keterangan:

$P \quad=$ Persentase Validitas

$X \quad=$ Skor penilaian dalam satu item

$X i=$ Skor penilaian ideal dalam satu item

$100 \%=$ Konstanta

Data yang telah ditafsirkan melalui rumus tersebut dapat disimpulkan berdasarkan Tabel 1 menurut Akbar (2017) sebagai berikut: 
Tabel 1. Kriteria penilaian data persentase validitas produk

\begin{tabular}{lll}
\hline Persentase $(\%)$ & Kriteria Kelayakan & Keterangan \\
\hline $81-100 \%$ & Sangat layak & Tidak Revisi \\
$61-80 \%$ & Layak & Revisi Sebagian \\
$41,01-60 \%$ & Cukup Layak & Revisi (Uji coba ulang) \\
$21-40 \%$ & Kurang Layak & Revisi Totak (Uji coba ulang) \\
$81-100 \%$ & Sangat layak & Tidak Revisi \\
\hline
\end{tabular}

\section{HASIL DAN PEMBAHASAN}

Penelitian dan pengembangan aplikasi CPA menggunakan tujuh tahapan penelitian yang mengadaptasi Gall et al. (2003). Adapun tahapan penelitian yang telah dilaksanakan telah terskema dalam diagram alir pada Gambar 1 sebagai berikut:

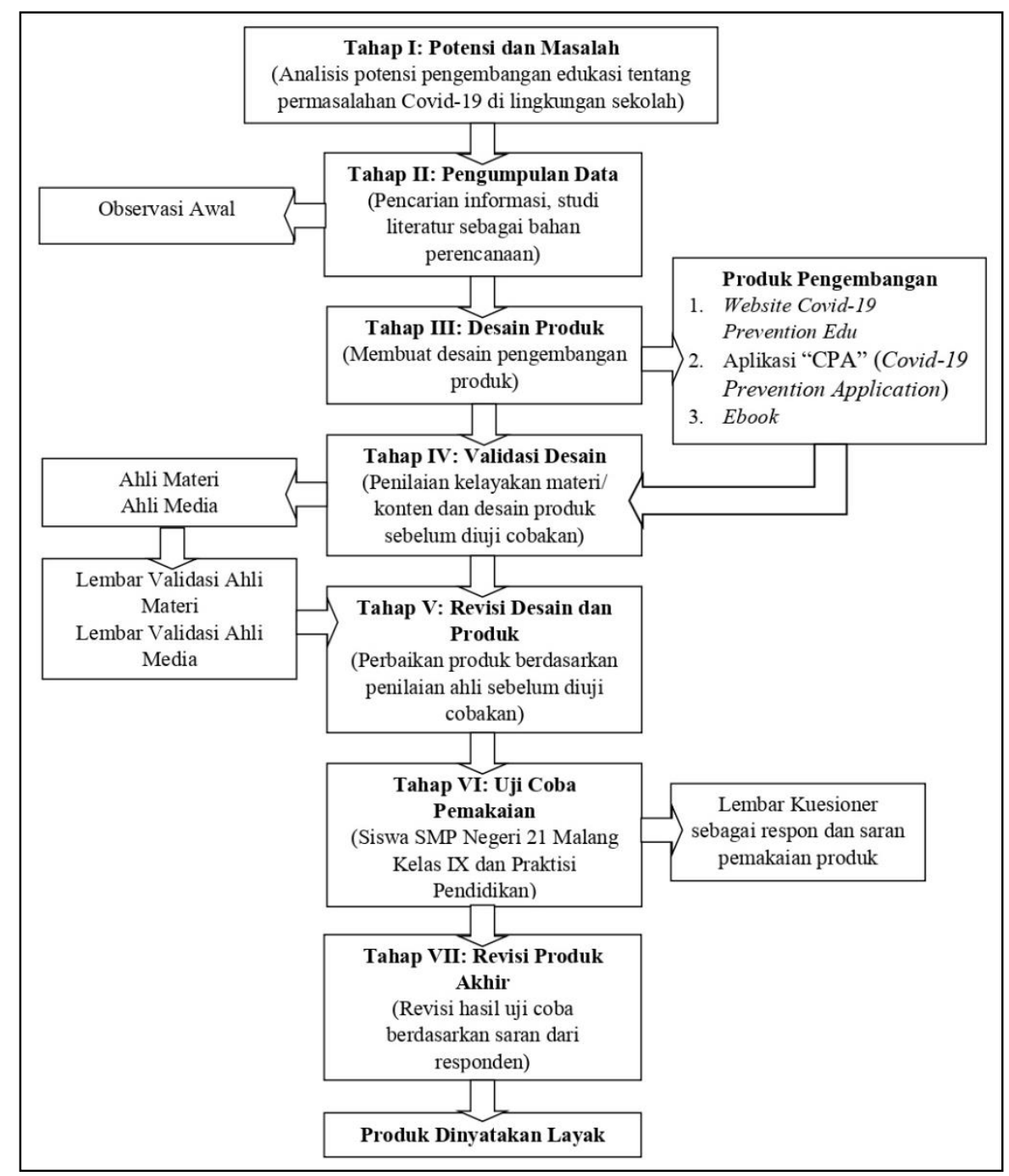

Gambar 1. Diagram alir tahapan penelitian dan pengembangan

Penelitian dan pengembangan ini diawali dengan menganalisis potensi dan masalah. Tahapan potensi dan masalah merupakan tahapan pra lapangan dengan meninjau adanya permasalahan yang ada di lingkungan siswa dan menemukan potensi untuk mengatasi permasalahan tersebut. Berdasarkan hasil potensi dan masalah dapat diketahui bahwa pembelajaran berbasis online yang dilaksanakan pada masa Pandemi Covid-19 membutuhkan suatu penyesuaian baru mengingat model pembelajaran online belum pernah dilaksanakan pada skala besar 
sebelumnya. Pembelajaran online ini didasarkan pada kebijakan pemerintah yang menyarankan agar melakukan pembatasan sosial sebagai upaya pencegahan Covid19 mengingat penyebaran Covid-19 telah merambah ke dunia pendidikan dan telah memakan korban sehingga sekolah dinyatakan sebagai klaster persebaran Covid19. Sekiranya dalam waktu lima bulan saja, terdapat 138 siswa dan santri yang positif Covid-19 dan ratusan lainnya diharuskan karantina mandiri karena melakukan kontak langsung dengan pasien teridentifikasi Covid-19 (Federasi Serikat Guru Indonesia, 2020). Hal tersebut telah mencerminkan bahwa harus ada upaya untuk meminimalisir tersebarnya Covid-19 di lingkungan sekolah. Upayaupaya tersebut dapat menjadi bentuk mitigasi bencana dan pengenalan Covid-19 bagi siswa agar mengetahui bahaya penyebaran Covid-19. Disisi lain, guru juga memerlukan adaptasi terhadap adanya fenomena Covid-19 dan penyesuain kegiatan pembelajaran sesuai dengan protokol kesehatan. Selain itu, pemerintah juga menganjurkan bahwa materi Covid-19 harus disampaikan dalam pembelajaran secara tersirat, maka dari itu diperlukan adanya media yang dapat mempermudah dalam melaksanakan pembelajaran di masa Pandemi Covid-19 ini. Berdasarkan hal tersebut dapat diketahui bahwa diperlukan adanya media yang dikemas dan dapat digunakan pada saat pembelajaran online maupun pembelajaran tatap muka sesuai protokol kesehatan sebagai bentuk upaya dalam meminimalisir penyebaran Covid19 dan berkaitan dengan materi pembelajaran. Menjawab adanya potensi tersebut, Aplikasi CPA perlu untuk dikembangkan sebagai bentuk literasi mitigasi bencana Covid-19.

Tahapan selanjutnya setelah menganalisis potensi dan masalah adalah pengumpulan data. Tahapan pengumpulan data juga dilaksanakan oleh peneliti terdahulu yaitu (N. Jannah et al., 2017), yang bertujuan untuk menggali data sebelum dilaksanakannya tahapan pengembangan. Pada penelitiannya, pengumpulan data dilaksanakan dengan menyerap informasi dari guru bahwa adanya kebutuhan pengembangan Ebook interaktif sebagai bahan ajar yang mempermudah penyampaian materi dan menganalisis konsep Kompetensi IntiKompetensi Dasar (KI-KD) serta mencari literatur yang terkait. Tidak jauh berbeda dengan hal tersebut, pengumpulan data pada penelitian ini dilaksanakan dengan kegiatan observasi dan wawancara yang dilaksanakan di SMP Negeri 21 Malang. Lokasi penelitian ditentukan berdasarkan wilayah sekitar lokasi merupakan zona merah penyebaran Covid-19 sehingga lokasi tersebut terdampak adanya Covid-19. Selain itu, SMP Negeri 21 Malang merupakan sekolah yang menerapkan kurikulum berbasis lingkungan dan termasuk sekolah adiwiyata yang mengutamakan kesehatan warga sekolah dan menciptakan lingkungan belajar yang ramah lingkungan. Kegiatan pembelajaran menggunkanan sistem online sesuai kebijakan pemerintah dengan mengaitkan materi dengan pencegahan Covid-19 dan kegiatan di sekolah sesuai dengan protokol kesehatan. Guru menyampaikan bahwa materi Covid-19 penting untuk disampaikan sebagai bentuk meminimalisir penyebarannya. Guru senantiasa menyampaikan kepada siswa agar selalu menjaga kebersihan dan mengikuti protokol kesehatan dalam pembelajaran. Adanya perubahan kebijakan dan penyesuaian kegiatan pembelajaran online membuat siswa mengalami kebosanan saat melaksanakan kegiatan pembelajaran. Disisi lain belum adanya media yang dapat menjadi literasi mitigasi bencana Covid-19. Konsep mitigasi materi bencana Covid-19 dapat dikaitkan dalam kehidupan sehari-hari dan erat kaitannya dengan pembelajaran IPS sehingga dapat dimasukkan dalam materi perubahan sosial mengingat terdapat banyaknya contoh kontekstual perubahan akibat adanya pandemi Covid-19. Materi perubahan sosial 
dimuat dalam KD 3.1 kelas IX yaitu 3.1 Menelaah perubahan keruangan dan interaksi antarruang negara-negara Asia dan benua lainnya yang diakibatkan faktor alam, manusia dan pengaruhnya terhadap keberlangsungan kehidupan manusia dalam ekonomi, sosial, pendidikan, dan politik. Konsep materi yang akan disampaikan dalan aplikasi CPA yaitu gambaran umum Covid-19, cara penularan Covid-19, gejala Covid-19, dampak akibat terpapar Covid-19, upaya pencegahan Covid-19, dan perubahan sosial akibat Covid-19.

Tahapan desain produk merupakan tahapan lanjutan setelah pengumpulan data. Produk yang dikembangkan berupa website dan aplikasi CPA. Desain produk diawali dengan membuat storyboard (rancangan) sebagai gambaran awal. Setelah rancangan telah disesuaikan dengan daya dukung pengembangan makan dilaksanakan proses mendesain. Desain website menggunakan platform Wordpress. Website yang berjudul "Covid-19 Prevention Edu” ini berfungsi untuk mempromosikan aplikasi CPA dan memudahkan pengguna untuk mengunduh aplikasi CPA. Tampilan website dapat dilihat pada Gambar 2.

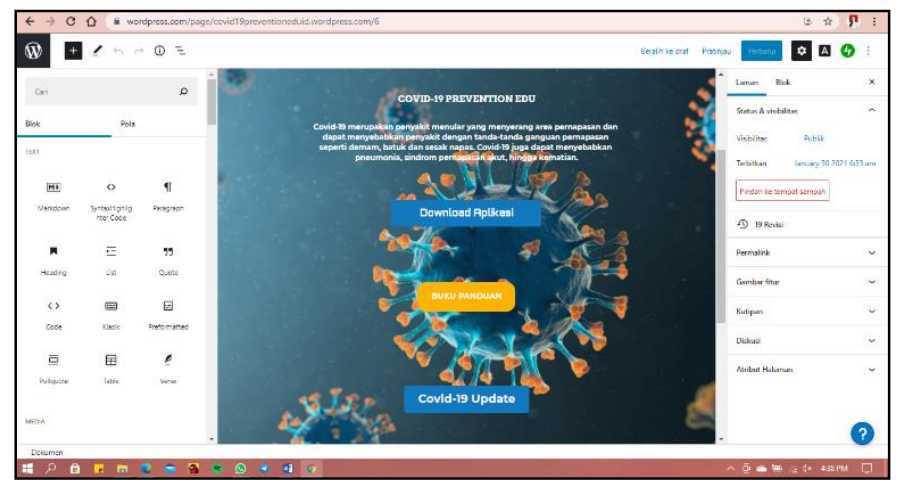

\section{Gambar 2. Pembuatan website "Covid-19 Prevention Edu"}

Pembuatan aplikasi CPA menggunakan platform Android Studio dengan bahasa pemrograman Java. Aplikasi CPA berisi kumpulan Ebook animasi tentang Covid-19 yang dilengkapi dengan fitur-fitur pendukung untuk memudahkan pengoperasiannya. Sebelum mengakses aplikasi CPA, pengguna diharuskan log in dengan mencantumkan email, dan password kemudian pengguna langsung dapat membuka halaman utama dengan beberapa fitur untuk mempermudah membuka Ebook tentang Covid-19. Tampilan aplikasi dapat dilihat pada Gambar 3.

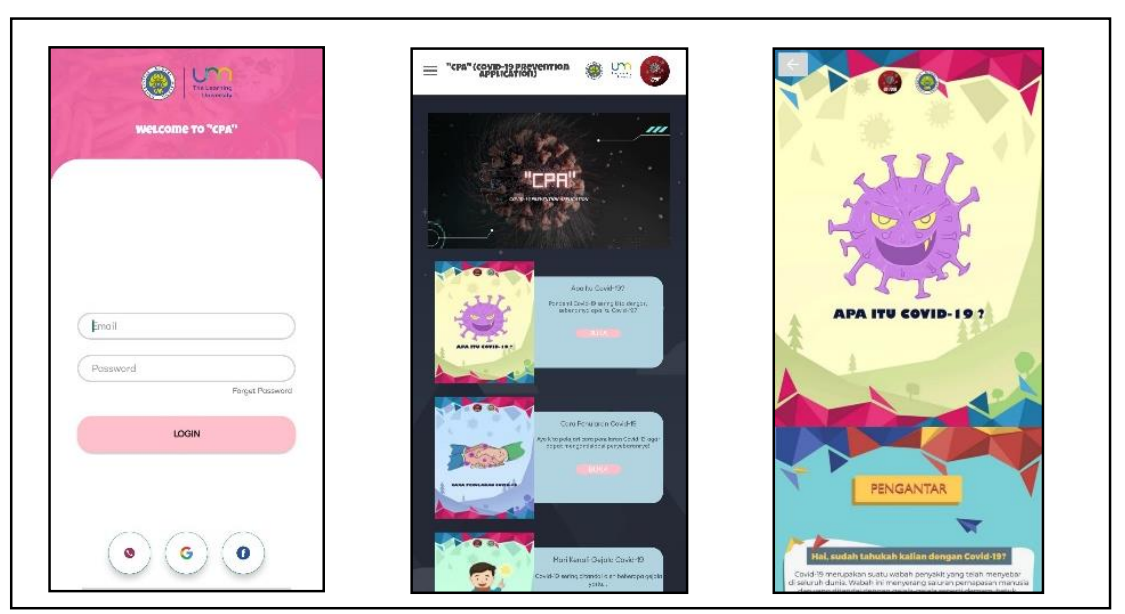

Gambar 3. Aplikasi CPA (Covid-19 Prevention Application) 
Tahapan setelah melakukan desain produk adalah validasi desain. Validasi desain dilaksanakan dengan menghadirkan ahli materi dan ahli media untuk melakukan penilaian secara rasional kelayakan Aplikasi CPA untuk diuji cobakan. Validasi materi dengan menilai kelayakan berdasarkan beberapa aspek yaitu aspek relevansi materi, aspek pengorganisasian materi, aspek evaluasi, aspek bahasa, dan aspek strategi pembelajaran. Adapun rekapitulasi data kuantitatif dapat dilihat pada Tabel 2 berikut:

Tabel 2. Rekapitulasi data kuantitatif hasil validasi materi

\begin{tabular}{clc}
\hline No & \multicolumn{1}{c}{ Aspek } & Skor \\
\hline 1 & Relevansi materi & 10 \\
2 & Pengorganisasian materi & 25 \\
3 & Evaluasi & 10 \\
4 & Bahasa & 12 \\
5 & Strategi pembelajaran & 13 \\
\hline \multicolumn{2}{r}{ Total Skor } & 70 \\
& Persentase & $87,5 \%$ \\
& Kriteria & Sangat Layak \\
\hline
\end{tabular}

Validasi pertama yang dilakukan adalah validasi materi. N. Jannah et al. (2017), menyatakan bahwa relevansi materi dengan kurikulum sebesar $100 \%$ yang mengartikan bahwa materi dalam Ebook dinyatakan valid untuk dijadikan bahan pembelajaran. Hal tersebut senada dengan penelitian ini, berdasarkan data kuantitatif telah menunjukkan bahwa validasi materi memperoleh kriteria "Sangat Layak" dengan persentase $87,5 \%$. Adapun data kualitatif dalam validasi media adalah memperbaiki pengolahan kata agar disesuaikan dengan siswa tingkat SMP dan memperhatikan diksi yang digunakan agar informasi dapat tersampaikan dengan jelas. Hasil dari validasi materi menyatakan bahwa secara rasional aplikasi CPA sangat layak diuji cobakan kepada siswa sebagai mitigasi bencana Covid-19.

Langkah selanjutnya adalah melaksanakan validasi media. Validasi media dilaksanakan dengan menilai Aplikasi CPA berdasarkan beberapa aspek yaitu aspek bahasa, aspek strategi pembelajaran, aspek rekayasa perangkat lunak, dan aspek tampilan visual. Adapun rekapitulasi data kuantitatif dapat dilihat pada Tabel 3 berikut:

\section{Tabel 3. Rekapitulasi data kuantitatif hasil validasi media}

\begin{tabular}{|c|c|c|}
\hline No & Aspek & Skor \\
\hline 1 & Bahasa & 12 \\
\hline 2 & Strategi pembelajaran & 24 \\
\hline 3 & Rekayasa perangkat lunak & 20 \\
\hline 4 & Tampilan visual & 18 \\
\hline & Total Skor & 74 \\
\hline & Persentase & $92,5 \%$ \\
\hline & Kriteria & Sangat Layak \\
\hline
\end{tabular}

Penelitian yang dikaji oleh N. Jannah et al. (2017), mengungkapkan bahwa penggunaan media berbasis Ebook memiliki nilai konstruksi (tampilan media) sebesar 100\% dan keterbacaan (bahasa) 96\% dinyatakan valid. Hal tersebut menjadi daya dukung bahwa penerapan Ebook dalam pembelajaran diharapkan dapat membantu proses pembelajaran menjadi lebih unteraktif. Hal ini relevan dengan validasi media pada penelitian ini. Berdasarkan validasi media, data 
kuantitatif menunjukkan bahwa pengembangan aplikasi CPA memperoleh persentase penilaian $92,5 \%$ yang menunjukkan pada kriteria sangat layak untuk diuji cobakan. Data kualitatif yang diperoleh adalah mempersiapkan media dengan sebaik mungkin agar tidak terjadi kesalahan teknis saat kegiatan uji coba. Setelah melaksanakan tahapan validasi, maka perlu dilaksanakan revisi produk sebelum uji coba dilakukan. Hal ini bertujuan agar produk yang akan diuji cobakan benar-benar telah layak untuk diterapkan pada siswa.

Kegiatan uji coba dilaksanakan pada siswa kelas IX.1 SMP Negeri 21 Malang sejumlah 35 siswa untuk mengetahui respons siswa. Penlialian diukur berdasarkan beberapa aspek yaitu bahasa, komponen aplikasi, pengorganisasian tampilan, dan penyajian materi. Tabel 4 menunjukkan hasil rekapitulasi data respons siswa pada uji coba penggunaan Aplikasi CPA.

Tabel 4. Rekapitulasi data kuantitatif respons siswa

\begin{tabular}{clc}
\hline No & \multicolumn{1}{c}{ Aspek } & Skor \\
\hline 1 & Bahasa & 360 \\
2 & Komponen aplikasi & 355 \\
3 & Pengorganisasian tampilan & 467 \\
4 & Penyajian materi & 717 \\
5 & Keseluruhan & 469 \\
\hline \multicolumn{2}{r}{ Total Skor } & 2.368 \\
& Persentase & $85 \%$ \\
& Kriteria & Sangat Layak \\
\hline
\end{tabular}

Tahapan uji coba juga dilaksanakan oleh N. Jannah et al. (2017), pada penelitiannya menunjukkan bahwa respons siswa terdapat $91,67 \%$ yang menunjukkan bahwa pengembangan Ebook layak untuk diterima siswa sebagai bahan pembelajaran. Hal tersebut juga sesuai dengan penelitian dan pengembangan ini yang juga melakukan tahapan uji coba respons siswa. Berdasarkan data kuantitatif menunjukkan bahwa respons siswa terhadap penggunaan Aplikasi CPA memiliki kriteria sangat layak yang menunjukkan bahwa tahapan uji coba yang telah dilaksanakan dapat membantu membuat siswa antusias dan termotivasi kembali dalam melaksanakan pembelajaran berbasis online melalui media-media menarik salah satunya adalah aplikasi CPA. Berdasarkan data kualitatif, siswa menyebutkan bahwa aplikasi CPA menarik dengan animasi-animasinya dan memudahkan dalam memahami materi tentang Covid-19. Selain itu, siswa dapat secara rasional mengaitkan pencegahan Covid-19 dengan materi pembelajaran yaitu perubahan sosial. Tahapan akhir dalam penelitian dan pengembangan ini adalah revisi akhir sebagai bentuk penyempurnaan media.

Secara keseluruhan, penggunaan aplikasi CPA dapat dinyatakan sangat layak untuk diterapkan dalam pembelajaran. Berdasarkan aspek-aspek yang dinilai dapat diketahui bahwa aplikasi CPA dengan berbasis Ebook dapat meningkatkan minat belajar siswa. Hal ini sesuai dengan penelitian yang digagas oleh (Rodhiah \& Roza, 2020), diperoleh hasil bahwa sebanyak $89,3 \%$ siswa dalam penelitiannya membutuhkan Ebook untuk menunjang pembelajaran dan dapat meningkatkan minat belajar. Hal tersebut menunjukkan bahwa pengembangan berbasis Ebook dapat menarik perhatian siswa sehingga dapat membangkitkan semangat belajarnya. Pengembangan berbasis Ebook juga memiliki segi kepraktisan secara fisik dan keefektivan dalam penggunaanya (U. Jannah, 2019). Hal ini sesuai dengan temuan saat kegiatan uji coba dimana pada pembelajaran online siswa lebih mudah membaca materi melalui Ebook yang dapat diakses melalui smartphone. Hal 
tersebut relevan dengan pendapat (Herlina, Muhammad Lutfi, 2018; Martha, Z. D., Adi, E. P., \& Soepriyanto, 2018) yang menjelaskan bahwa melalui pembelajaran online (mobile learning) dapat meningkatkan perhatian, motivasi dan hasil belajar siswa. Berdasarkan hasil pengembangan ini, media aplikasi berbasis Ebook dapat meningkatkan motivasi belajar siswa melalui animasi-animasi yang dikemas semenarik mungkin. Kemenarikan penggunaan Aplikasi berbasis Ebook sesuai dengan penelitian dan pengembangan yang dilakukan oleh (Hidayat et. al., 2017). Hasil penelitian menyatakan bahwa Ebook yang dikembangkan mencapai nilai 3,12 yang berarti bahwa Ebook merupakan media yang menarik.

Pengembangan aplikasi CPA juga memberikan kesempatan kepada siswa untuk lebih banyak menggali pengetahuannya dan berpikir logis. Siswa diarahkan untuk mengkonstruksikan sendiri pengetahuan yang didapatkannya melalui kegiatan diskusi. Hal ini sejalan dengan penerapan teori belajar konstruktivisme. Menurut Supardan (2016), konstruktivisme merupakan paham yang mendorong siswa untuk memberikan jawaban-jawaban terbuka dan mendiskusikan tentang subjek yang dikajinya dalam menyusun suatu pengetahuan. Hal ini didukung dengan pendapat Mustafa \& Roesdiyanto (2021) dan S. A. Nugroho (2016), teori belajar konstruktivisme menekankan pada belajar yang merupakan proses pembentukan pengetahuan secara mandiri oleh siswa. Penerapan aplikasi CPA dalam pembelajaran tentu didasarkan pada teori-teori pendukung agar tujuan penelitian dapat tersampaikan. Tujuan dalam pengembangan aplikasi CPA adalah sebagai literasi mitigasi bencana Covid-19 yang dikaitkan dengan materi perubahan sosial. Hal tersebut sesuai dengan penerapan teori belajar konstruktivisme dimana pembelajaran akan mudah dimengerti oleh siswa ketika siswa diberikan kesempatan berpikir secara logis sesuai dengan fenomena yang ada di sekitarnya melalui kegiatan diskusi. Menurut Suprapti (2018), teori belajar konstruktivisme menekankan pada belajar yang merupakan proses pembentukan pengetahuan secara mandiri oleh siswa. Hal ini diharapkan untuk siswa aktif berpikir dan menyusun konsep agar makna dalam pembelajaran dapat tersampaikan sesuai dengan pernyataan tersebut, diperlukan perancang pembelajaran dan pengembang program-program pembelajaran agar dapat menciptakan lingkungan belajar. Menurut Nugroho (2016), penerapan teori belajar konstruktivisme dalam proses pembelajaran dapat meningkatkan keaktifan dan dapat memberikan motivasi siswa dalam meningkatkan hasil belajarnya. Penggunaan media dalam penerapan pembelajaran berbasis konstruktivisme dapat menjadi pendukung dalam tercapainya tujuan pembelajaran (Sugrah, 2020). Penerapan teori belajar konstruktivisme dalam pengembangan aplikasi CPA tercermin pada pelaksanaan kegiatan pembelajaran yang memberikan kesempatan siswa untuk mendalami lebih lanjut terkait materi melalui kegiatan berdiskusi dengan teman.

Pengembangan aplikasi CPA berkaitan dengan penerapan teori kerucut pengalaman Edgar Dale yang mengatakan bahwa hasil belajar seseorang dapat diperoleh secara langsung (konkret) melalui pengalamannya. Penglaman tersebut dapat dibentuk melalui visual akan mempengaruhi keaktifannya dalam belajar (Zaman, 2020). Teori ini memberikan gambaran bahwa pengalaman belajar siswa dapat melalui berbagai macam proses yaitu pengalaman individu siswa dari apa yang ia dipelajari ataupun proses mengamati dan mendengarkan media tertentu (Arif, 2021; Aryani et al., 2021; Misbah et al., 2021; Rohani, 2019). Teori ini berorientasi pada pemahaman siswa yang dapat dibentuk melalui pengalamanpengalaman yang dialaminya. Menurut Rohani (2019), teori ini menggambarkan bahwa pengalaman belajar siswa didapat dari berbagai macam proses yaitu 
pengalaman siswa dalam mempelajari suatu pengetahuan atau suatu proses pengamatan terhadap suatu media. Jika siswa mengalami langsung dan mendapatkan pengalaman nyata maka materi dapat terserap dengan baik dan hasil belajar meningkat. Hal ini senada dengan pendapat Hadi (2017) yang menjelaskan bahwa siswa merasakan pengalaman belajar bermakna ketika guru menghadirkan suasana belajar yang dapat dirasakan dengan menggunakan semua panca inderanya. Semakin banyak panca indera yang digunakan siswa saat belajar, pengetahuan akan dapat mudah diserap oleh siswa (Huda, 2016; Khoirun, 2017; Sari, 2019; Syamsidar et al., 2018). Penggunaan aplikasi CPA dalam pembelajaran tentu menerapkan pemanfaatan panca indera pada siswa melalui animasi-animasi yang disajikan agar memberikan pengalaman bagi siswa sehingga siswa dapat merekam pengetahuan yang ia dapatkan.

Aplikasi CPA merupakan suatu sistem informasi yang dapat membantu siswa untuk meningkatkan literasinya. Hal ini relevan dengan penerapan teori belajar sibernetik yang berorientasi pada sistem informasi. Pada dasarnya, sistem informasi dapat membantu siswa untuk membentuk ingatannya dan mempermudah siswa dalam mengakses pengetahuannya secara mandiri. Menurut pendapat (Ratnawati, 2016), teori sibernetik sekilas hampir sama dengan teori kognitif yang berorientasi pada proses, tetapi teori ini lebih mengutamakan sistem informasi yang digunakan dalam proses belajar. Sejalan dengan berkembangnya ilmu pengetahuan dan informasi, teori belajar sibernetik mengasumsikan bahwa belajar merupakan proses pengolahan informasi. Teori ini mengutamakan sistem informasi sebagai bahan pembelajaran bagi siswa. Tujuan dari penggunaan sistem informasi dalam pembelajaran agar dapat mengefisiensikan pembelajaran dan dapat meningkatkan memori siswa (Salim \& Maryanti, 2017). Menurut Suminar (2016) teori belajar sibernetik merupakan upaya dalam membantu siswa untuk mencapai tujuan belajarnya berdasarkan unsur-unsur pemikiran (kognitif) lewat proses pengolahan informasi yang nantinya akan menanamkamkan memori pada siswa dan siswa memori tersebut merupakan bentuk pemahaman dalam pembelajaran. Hal tersebut sejalan dengan pernyataan Yunus (2018) yaitu pembelajaran dengan menerapkan teori sibernetik dapat mempermudah akses untuk memperoleh informasi dan menghilangkan kemungkinan sulitnya belajar ketika pendidik tidak dapat hadir di kelas. Aplikasi CPA dalam pembelajaran berfungsi sebagai sistem informasi yang dapat memberikan siswa pengetahuan dan mempermudah siswa dalam memahami materi perubahan sosial.

\section{SIMPULAN}

Berdasarkan uraian dan temuan pada penelitian dan pengembangan aplikasi CPA, dikemukakan kesimpulan yaitu: Pengembangan aplikasi berbasis Ebook dinyatakan valid. Hasil rekapitulasi berdasarkan validasi dan uji coba pengembangan Aplikasi CPA memiliki kriteria sangat layak untuk menjadi sumber belajar bagi siswa SMP. Implementasi dalam penerapan aplikasi CPA yaitu siswa secara penuh dapat menggunakan aplikasi sebagai bentuk literasi mitigasi bencana Covid-19 yang relevan dengan pembelajaran IPS dengan materi perubahan sosial. Produk aplikasi CPA berbasis Ebook direkomendasikan untuk: 1) siswa dengan memanfaatkan aplikasi android sebagai sarana siswa untuk lebih memahami materi dengan menyenangkan dengan animasi yang disajikan, 2) guru, sebagai sumber belajar yang interaktif dan menarik agar memudahkan penyampaian materi perubahan sosial dan literasi mitigasi bencana Covid-19. Saran pada penelitian ini diharapkan dapat melakukan uji coba skala besar dengan mengukur tingkat 
efektivitasnya. Pengembangan lebih lanjut dapat menyempurnakan aplikasi CPA dengan memberikan fitur audio dan video yang kemudian dapat disebar luaskan melalui platform PlayStore.

\section{DAFTAR PUSTAKA}

Arif, M. (2021). Penggunaan video untuk meningkatkan hapalan anak usia dini. Jurnal Motoric Media of Teacing and Children, 5(1), 6.

Aryani, N., Desyanty, E. S., \& Listyaningrum, R. A. (2021). Pemanfaatan Teknologi pembelajaran sebagai upaya meningkatkan motivasi belajar dalam pendidikan nonformal dan informal. Prosiding Seminar Nasional Peta Jalan Pendidikan Dan Rancangan Undang-Undang Sistem Pendidikan Nasional, 66-72.

Federasi Serikat Guru Indonesia. (2020). FSGI catat ratusan guru terkena corona, 42 orang di antaranya meninggal_Federasi Serikat Guru Indonesia.

Firman, F., \& Rahayu, S. (2020). Pembelajaran online di tengah pandemi Covid-19. Indonesian Journal of Educational Science (IJES), 2(2), 81-89. https://doi.org/10.31605/ijes.v2i2.659

Gall, M. ., Gall, J. ., \& Borg, W. . (2003). Educational research: An introduction (7th ed.). Allyn \& Bacon.

Hadi, S. (2017). Efektivitas penggunaan video sebagai media. Prosiding TEP \& PDs, Tema: 1 No, 96-102.

Hairi, P. J. (2020). Implikasi hukum pembatasan sosial berskala besar terkait pencegahan Covid-19. Info Singkat Bidang Hukum, 12(April), 1-6.

Herlina, Muhammad Lutfi, A. (2018). Pengembangan aplikasi mobile learning pra nikah berbasis android dengan menggunakan teknologi unity 3D V5. JURNAL INSTEK: Informatika Sains Dan Teknologi, 3(2), 211-220.

Hidayat, A., Suyatna, A., \& Suana, W. (2017). Pengembangan buku elektronik interaktif pada materi fisika kuantum kelas XII SMA. Jurnal Pendidikan Fisika, 05(02), 87-101.

Huda, M. (2016). Pembelajaran berbasis multimedia dan pembelajaran konvensional (Studi komparasi di MTs Al-Muttaqin Plemahan Kediri). Jurnal Penelitian, 10(1), 125-146. https://doi.org/10.21043/jupe.v10i1.865

Jannah, N., Fadiawati, N., \& Tania, L. (2017). Pengembangan e-book interaktif berbasis fenomena kehidupan sehari-hari tentang pemisahan campuran. Jurnal Pendidikan Dan Pembelajaran Kimia, 6(1), 186-198.

Jannah, U. (2019). Pengembangan ebook interaktif menulis teks eksplanasi berbasis GLS Untuk siswa kelas XI SMAN 1 Tenggarang Bondowoso. Nosi, 7(2), 1-7.

Khoirun. (2017). Kerucut pengalaman Edgar Dale. In Civitas UNS.

Marbun, P. (2020). Disain pembelajaran online pada era dan pasca Covid-19. CSRID Journal, 12(2), 129-142.

Martha, Z. D., Adi, E. P., \& Soepriyanto, Y. (2018). E-book berbasis mobile learning. Jurnal Kajian Teknologi Pendidikan, 1(2), 109-114.

Misbah, M., Sahibudin, M., Islam, U., Prof, N., \& Saifuddin, K. H. (2021). Dale's theory dan Bruner's theory (analisis media dalam pentas wayang santri ki enthus susmono). 8(2), 225238.

Mohammed, M., Ebied, A., Ahmed, S., \& Rahman, A. (2015). The effect of interactive e-book on students' achievement at najran university in computer in education course. Journal of Education and Practice, 6(19), 71-83.

Mustafa, P. S., \& Roesdiyanto, R. (2021). Penerapan teori belajar konstruktivisme melalui model PAKEM dalam permainan bolavoli pada sekolah menengah pertama. Jendela Olahraga, 6(1), 50-56. https://doi.org/10.26877/jo.v6i1.6255

Nabila, P. W., Rudibyani, R. B., \& Sofya, E. (2019). Efektivitas media e-book untuk meningkatkan motivasi dan penguasaan konsep siswa. Jurnal Pendidikan Dan Pembelajaran Kimia, 8(3), $469-481$.

Nasution, S., \& Islam. (2018). Pengembangan model pembelajaran bahasa Arab Arabi : Journal of Arabic Studies. Arabi, 3(2), 121-144.

Nugroho, P. (2016). Pengembangan Model pembelajaran IPS terpadu berbasis lingkungan. Jurnal Ilmu Pendidikan Universitas Negeri Malang, 22(2), 114077.

Nugroho, S. A. (2016). Peningkatan keaktifan dan hasil belajar siswa melalui penerapan teori konstruktivisme berbasis media wondershare quizcreator. Indonesian Journal of Curriculum and Educational Technology Studies, 4(2), 73-78. https://doi.org/10.15294/ijcets.v4i2.14310

Ratnawati, E. (2016). Karakteristik teori-teori belajar dalam proses pendidikan (perkembangan 
psikologis dan aplikasi). Edueksos: Jurnal Pendidikan Sosial \& Ekonomi, 4(2), 1-23.

Rina Tiya Lestari 1 , Eka Pramono Adi 2, Y. S. 3. (2016). Ebook media pembelajaran interaktif. $E$ - ISSN: 2615-8787 E-BOOK, 71-76.

Rodhiah, S. A., \& Roza, L. (2020). Hasil analisis kebutuhan pengembangan ebook berbasis multipel representasi. Prosiding Seminar Nasional Pendidikan Fisika FITK UNSIQ, 2(1), 143-149.

Rohani. (2019). Diktat media pembelajaran. 95.

Salim, S., \& Maryanti, E. (2017). Pengembangan perangkat pembelajaran matematika melalui teori pembelajaran sibernetik berbantuan software derive. Jurnal Riset Pendidikan Matematika, 4(2), 229. https://doi.org/10.21831/jrpm.v4i2.16068

Sari, P. (2019). Analisis terhadap kerucut pengalaman Edgar Dale dan keragaman gaya belajar untuk memilih media yang tepat dalam pembelajaran. Mudir: Jurnal Manajemen Pendidikan, I(1), 58-78.

Sugrah, N. U. (2020). Implementasi teori belajar konstruktivisme dalam pembelajaran sains. Humanika, 19(2), 121-138. https://doi.org/10.21831/hum.v19i2.29274

Suminar, T. (2016). Tinjauan filsafati (ontologi, epistemologi dan aksiologi manajemen pembelajaran berbasis teori sibernetik. Edukasi, 1(2).

Supardan, D. (2016). Teori dan praktik pendekatan konstruktivisme dalam pembelajaran. Edunomic, $4(1), 1-12$.

Suprapti, E. (2018). Penerapan teori belajar konstruktivisme untuk meningkatkan hasil belajar mahasiswa pada mata kuliah matematika dasar. MAJAMATH: Jurnal Matematika Dan Pendidikan Matematika, 1(1), 24. https://doi.org/10.36815/majamath.v1i1.116

Syamsidar, Maruf, U. M. M., \& Hustim, R. (2018). Pembelajaran fisika berbasis cone of experience Edgar Dale. Jurnal Pendidikan Fisika, 6, 1-12.

WHO Indonesia. (2020). WHO Indonesia |World Health Organization.

Wijayanti, M. (2018). Pengembangan e-book IPA fisika berbasis program sigil peserta didik SMPN 23 Simbang Kabupaten Maros. Seminar Nasional Fisika 2018, 1-5.

Yunus, R. (2018). Teori belajar sibernetik dan implementasinya dalam pelaksanaan diklat. Journal of Education Science, 4(2), 32-41.

Zaman, B. (2020). Penerapan active learning dalam pembelajaran PAI. Jurnal As-Salam, 4(1), 1327. https://doi.org/10.37249/as-salam.v4i1.148 